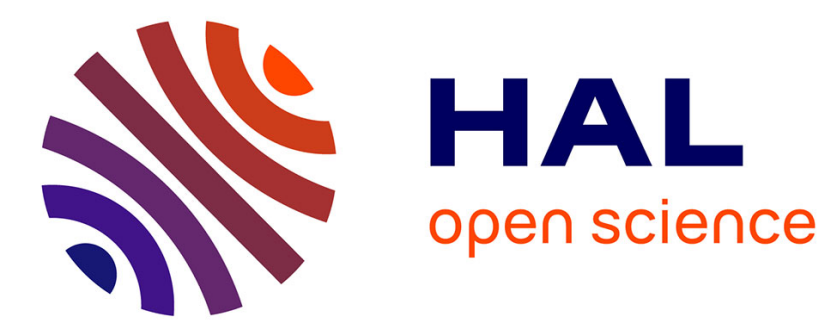

\title{
Souvenirs sur le prince Albert de Monaco et son oeuvre préhistorique
}

\author{
Henri Breuil
}

\section{To cite this version:}

Henri Breuil. Souvenirs sur le prince Albert de Monaco et son oeuvre préhistorique. Bulletin de la Société préhistorique française, 1951, 5-6, pp.287-288. halshs-00956471

\section{HAL Id: halshs-00956471}

https://shs.hal.science/halshs-00956471

Submitted on 6 Mar 2014

HAL is a multi-disciplinary open access archive for the deposit and dissemination of scientific research documents, whether they are published or not. The documents may come from teaching and research institutions in France or abroad, or from public or private research centers.
L'archive ouverte pluridisciplinaire HAL, est destinée au dépôt et à la diffusion de documents scientifiques de niveau recherche, publiés ou non, émanant des établissements d'enseignement et de recherche français ou étrangers, des laboratoires publics ou privés. 
Extrait de la $S . P . F ., \mathrm{n}^{\circ}$ 5-6, mai-juin 1951.

\section{inticioris \\ in il Sguvenirs sur le Prince Albert de Monaco 1. in in: et son œuvre préhistorique. PAR}

\section{l'Abbé H. BREUIL,}

de l'Institut.

C'est le 10 novembre 1904 que j'appris de mon vieux maitre Emile Cartailhac la décision de son Altesse le Prince Albert de Monaco de prendre à sa charge la coûteuse publication des fresques préhistoriques que, 2 ans auparavant, le premier m'avait emmené relever près de Santander. M. Saige Président du Tribunal de Monaco, ami d'enfance de Cartailhac et confident de ses embarras, eut l'idée de montrer au Prince mes beaux pastels des magnifiques bisons qui décorent le plafond de la caverne d'Altamira. Le Prince en réclama de suite l'édition à son compte, mais demanda celles de toute découverte analogue; il proposa à Cartailhac, au $\mathrm{D}^{\mathrm{r}}$ Capitan et à moi, un contrat formel, origine des magnifiques livres sur les grottes ornées d'Altamira (Espagne), Font de Gaume et Combarelles (Dordogne), cavernes cantabriques, Pasiega et Pileta, également espagnoles.

Les circonstances d'après la guerre $14-18$ et la mort du Prince, le 26 Juin 1922, ont arrêté l'essort de ces publications, dont 4 volumes des Pyrénées françaises et un de Dordogne demeurent inédits, sans parler des roches peintes orientales d'Esnogne.

C'est probablement en 1906, lors du Congrès préhistorique de Monaco, qu'invité à dîner au Palais avec d'autres notables, je le rencontrai personnellement. Nous visitâmes alors les grottes de Grimaldi, où il avait fait exécuter d'immenses fouilles, et étudier les magnifiques récoltes en provenant au Musée anthropologique.

Mais, le 31 décembre 1908 , le Prince me recevait, manifestant son désir de fouilles à ses frais dans les grottes de Santander, lourd travail pour lequel je sollicitai de lui la collaboration de mon grand ami allemand Hugo Obermaier, alors Privat-docent à Vienne. Le prince en agréa la suggestion et apprécia hautement la valeur scientifique et le grand caractère moral et humain (il ètait paci(iste) de men ami. Des fouilles furent donc décidées, d'accord avec mon collaborateur local Alcalde del Rio, et le prince me fit prévoir sa visite.

Le 10 juillet 1909, il nous informa qu'il mettait le cap sur Santander avec son yacht de travail, la Princesse Alice. Obermaier devait venir de Vienne (il n'y avait pas d'avion en ce temps-là) et les petites voies ferrées d'Espagne du Nord n'ont que des trains tardigrades. Quand nous arrivâmes à Santander, le 19 juillet 1909, la jolie silhouette de la Princesse Alice se détachait au milieu de la rade, objet de la curiosité des citadins. Nous fûmes de suite à bord pour tirer nos plans : trois excursions furent prévues, Covalanas a l'Est aux frontières de Biscaye; Castillo (Puenteviesgo) grande caverne ornée, à fouilles commencées l'année précédente; enfin Altamira, «la Chapelle sixtine »de l'art quaternaire.

Quelque illuminé du pays voulut entraîner le Prince à une autre 
grotte de Suances, non loin d'Altamira, «plus belle, disait-il, que celle-ci » mais, défiant, le Prince m'y dépêcha; c'était une grotte toute fraîchement ornée de stupides figures. Mais le Palacio contigu avait préparé, à grand luxe de cristallerie, un champagne d'honneur pour l'Hôte princier et sa suite. Je fus le seul, de fort mauvaise humeur, à en vider une coupe.

Nos trois excursions, réalisées sous la conduite d'Obermaier et de moi-même, impressionnèrent vivement son Altesse, et ce fut à regret qu'il quitta cette terre d'Espagne où tant de souvenirs de sa jeunesse le rattachaient. Le 25 juillet, la Princesse Alice prenait le large.

Le 31 Octobre, un télégramme me demandait de me rendre au Château de Marchais, près de Laon. Après déjeuner, le Prince, en tenue de chasse avec son fusil, m'emmena dans les bois; au bord d'une tourbière, nous nous assîmes; il s'ouvrit alors à moi de son intention de fonder, sous la direction du $\mathrm{P}^{r}$ Boule, un Institut de Paléontologie Humaine où Obermaier et moi pourrions continuer nos recherches. Il me chargeait d'élaborer pour lui, avec M. Boule, qui en avait eu la première idée, un projet détaillé que je lui rapportai le 21 décembre suivant à Marchais; cette fois il me confia un fusil dont je me servis honorablement, faisant le coup du roi sur un faisan lancé à toute vitesse droit sur moi.

Le projet fourni était, sur les locaux, sans aucun esprit de luxe; mais, sur ce point, le Prince voulut faire honneur à sa haute situation.

Ce ne fut que le 24 juillet 1910 que la fondation fut officiellement coństituée. Le 16 novembre, le Conseil d'Administration se forma; le 25 janvier 1911 les Professeurs furent nommés et le Prince désigna, come Secrétaire, M. H. Neuville, son collaborateur en Zoologie maritime.

La tourmente 1914-18 nous priva fort malheureusement du très précieux concours d'Obermaier que le Prince n'abandonna jamais. Le 23 décembre 1920, eut lieu l'inauguration solennelle du nouvel Institut par le Prince Albert et le Président de la République Millerand, et la vie de cet organisme reprit tant bien que mal mais sans grandes facilités. De longues années, je fus pratiquement seul à en assurer l'enseignement, tenir et organiser les collections et le résultat des fouilles. Mais les nouvelles libéralités du Prince ne purent qu'atténuer les résultats d'une crise que la dernière guerre rendit plus aiguë encore.

A la direction quelque peu autocrate du $\mathrm{P}^{\mathrm{r}}$. Boule, décédé en 1940, succéda celle, pleine de sagesse et de dévouement, de M. le $\mathrm{Pr}^{\mathrm{r}} \mathrm{Va}$ lois.

Maintenant, dernier survivant de la fondation du Prince, je reporte ma pensée respectueuse et reconnaissante vers lui, dont la physionomie douce et triste reflétait le tourment de vivre pour élever, en promouvant l'idéal désintéressé de la Science, le niveau moral de l'humanité et son culte de la Vérité mieux connue, et de la Paix entre les hommes de bonne volonté de plus en plus nombreux à son service. 